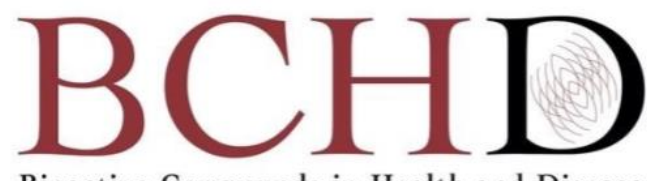

Bioactive Compounds in Health and Disease

\title{
Nutrition communication about low FODMAP diet in irritable bowel syndrome (IBS) and small intestinal bacterial overgrowth (SIBO) in Thai healthcare practitioners
}

\section{Varit Srisukthaveerat ${ }^{1^{*}}$, Wittayatorn Tokaew ${ }^{1,2}$, Supaporn Sridee ${ }^{1,2}$, Kamon Chaiyasit ${ }^{1}$}

${ }^{1}$ Curriculum of Communication Innovation for Political and Local Administration, Sukhothai Thammathirat Open University, Thailand; ${ }^{2}$ Department of Communication Art, Sukhothai Thammathirat Open University, Thailand.

*Corresponding author: Varit Srisukthaveerat, Curriculum of Communication Innovation for Political and Local Administration, Sukhothai Thammathirat Open University, Thailand.

Submission Date: April 5 ${ }^{\text {th }}, 2021$; Acceptance Date: June 14th ${ }^{\text {th }}, 2021$; Publication Date: June $21^{\text {st }}, 2021$

Please cite this article as: Srisukthaveerat V., Tokaew W., Sridee S., Chaiyasit K. Nutrition communication about low FODMAP diet in irritable bowel syndrome (IBS) and small intestinal bacterial overgrowth (SIBO) in Thai healthcare practitioners. Bioactive Compounds in Health and Disease. 2021; 4(6): 93-99. DOI: https://www.doi.org/10.31989/bchd.v4i6.798

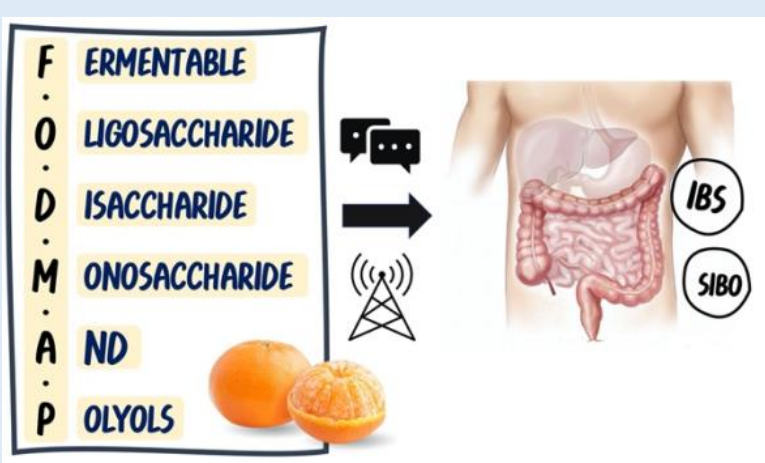

FODMAP is a therapeutic diet which is recommended for Irritable Bowel Syndrome (IBS) and Small Intestinal Bacterial Overgrowth (SIBO) patients. However, this diet has not been practiced widespread among Thai healthcare practitioners. As a matter of fact, these practitioners are familiar with a great number of diseases and closely well-educated with healthcare issues, they would significantly hold credibility affecting the medical usage to the society. Consequently, this article aims to educate all the staff in the healthcare and medical industry to gain sufficient knowledge of low FODMAP and be able to apply for further development.
} 
Keywords: nutrition communication, Low FODMAP, IBS, SIBO

(CFFC 2021. This is an Open Access article distributed under the terms of the Creative Commons Attribution 4.0 License (http://creativecommons.org/licenses/by/4.0)

\section{INTRODUCTION}

Communication has been included in everyday life [1], applying in various situations, talking, studying, working, etc. Based on the communication method on a daily basis, the main components which are sender, message, communication channel, and receiver, [2] work together to complete the processing loop of communication creating more understanding. On the other hand, the message is able to be sent and received either in one-way or twoway communication [3-4]. Besides these four primary components in the communication method, there are some internal and external factors causing more or less to the communication consequences in the deeper dimensions such as the Language, Emotions, Beliefs, Environment, Organizational, and etc [5-6]. Interestingly, it is necessary to in-depth perceive the specific communication context for the most effective outcome in a particular circumstance. Therefore, the healthcare practitioners are accredited in medical expertise due to the professional experiences; it would be highly influential to convey this message via their voices [7].

According to the research by Paweena Surinprateep et al. [8] on "The Factors Influencing Pregnant Women's Seeking of Health Information", the medical staff are not the learners who only take care of the patients. Hence, they took another role as educators giving the knowledge to society. Besides receiving the knowledge, they consider giving back as a duty to return their merit for people's welfare and better living. Although the low FODMAP has not been increasingly widespread among the medical industry at the present, its significant remedial potential would create prominent benefits to the public which inclines to be adopted by the healthcare practitioners in due time.

\section{REVIEW}

Communication in Healthcare and Nutrition: Communication in healthcare and nutrition is progressively concerned due to its impact in a wide range such as health promotion, prophylaxis, disease control, or even diet therapy [9-11]. Regarding the increase in social healthcare education, the trend in diet treatment is also increasing in the mass population accordingly. Moreover, communication technology was developed for easier accessibility at the present time causing the healthcare content distribution in various platforms and media channels. Regarding the accumulation by the Department of Provincial Administration, the Ministry of Interior, the current number of Thai population who are more than 60 years old is responsible up to $11,627,130$ from a total population of $66,186,727$, which is accounted to 17.57 in percentage [12]. Therefore, the food innovation entrepreneurs continuously encouraged healthcare education for marketing purposes on a corporate scale for the upcoming aging society in Thailand. The nurturing rate of the elder family 
members also rose, particularly the food and nutrition aspect which is considered causing the effect on health issues in the long run.

The audiences in the current trend are actively encouraged to create their own content by the rapid increase of the various communication channels among social media platforms [13-14] as well as the content receivers correspondingly react to the content by the creators. Particularly, the credibility in the healthcare content would be highly elevated when it was created by the medical staff due to their well-grounded expertise and direct experiences. This knowledge could not only be applied to medical treatment but also include content sharing for public education. When the medical staff act as the message senders, it could be considered as one of the crucial factors affecting the message receivers' attitude on credibility. Coherently to Herbert C. Kelman's idea [15], compliance would be created in oneself when a person accepts the influencing power from someone and expects to receive satisfaction from that power. There is a kind of gastrointestinal disease which is originated by Small Intestinal Bacterial Overgrowth (SIBO) - the excess and imbalance of small intestinal bacteria, consisting of flatulence, abdominal distension, and gas in the stomach, leading to Irritable Bowel Syndrome (IBS) with Diarrhea or Constipation afterward [16]. Despite the general symptoms only tend to last temporarily for periodic irritation [17-19], the chronic symptoms can cause some major effects to the overall quality of life, even digestion disruption in some nutritions. The medical report in 2016 clearly stated that Irritable Bowel Syndrome (IBS) can be found in $10-15 \%$ of the global population. The majority of the patients with minor symptoms accounted for $40 \%$, moderate and severe symptoms accounted for $35 \%$ and $25 \%$ respectively [20]. The doctors regularly apply medical treatment methods with antibiotics for the disease caused by Small Intestinal Bacterial Overgrowth (SIBO), while the Irritable Bowel Syndrome (IBS) would be treated with symptomatic treatment by the public health policy. The unsatisfactory symptoms still happen from time to time. Some medical practitioners might not truly recognize how the symptoms occurred, hence apply the symptomatic treatment due to the patients' illness. The majority of IBS patient's symptoms are related to the foods, particularly the carbohydrate [21]. Each IBS patients are likely to convey different symptoms due to the 4 disease types IBS-C (constipation), IBS-D (diarrhea), IBS-M (mixed), and IBS-U (unsubtyped) [22]. All of the above symptoms and diseases can be controlled by diet therapy as in this case of Low FODMAP [23-24].

In terms of the communication in healthcare content, the medical staff have been increasingly included due to their credibility and influencing power to the society. Besides, the change in society actively encourages people to be interested in wellbeing and healthcare, also reliable healthcare content by well-grounded medical staff is available for sourcing online. Interestingly, the association between Low FODMAP therapeutic nutrition to Irritable Bowel Syndrome (IBS) and Small Intestinal Bacterial Overgrowth (SIBO) symptom control is one of the topics worth spreading among medical staff and to the public for industry development purposes.

What is FODMAP Diet: FODMAP is a cluster diet in carbohydrate type, able to be fermented to produce gas and alcohol sugar. The term FODMAP was invented by Gibson and Shepherd [25] to call this type of carbohydrate originated by the below initials. The Low FODMAP component is shown in figure 1. 


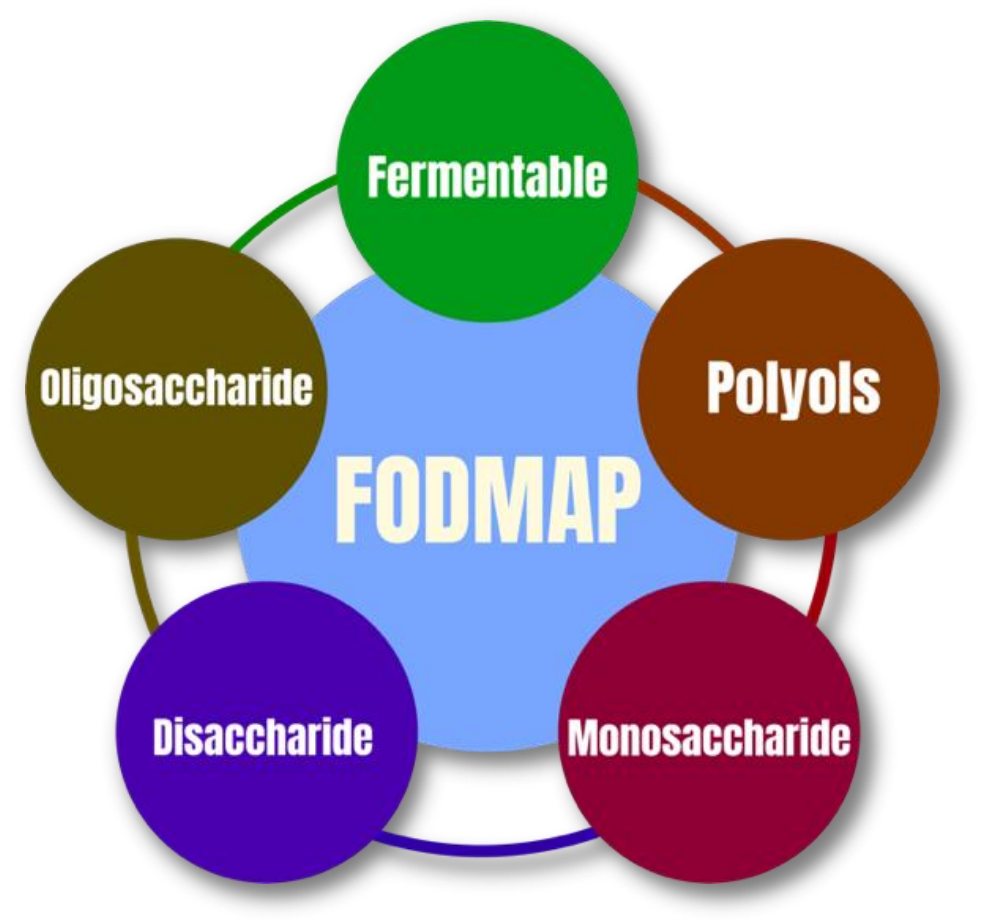

Figure 1. Composition of FODMAP diet

Fermentable $=$ Capable of producing gas, sugar, or even alcohol by a chemical process

Oligosaccharide $=$ Fructan, Galactan

Disaccharide $=$ Sucrose, Lactose, Maltose

Monosaccharide $=$ Fructose, Glucose, Galactose

Polyols = Sugar alcohol such as sorbitol

If any carbohydrate foods that the IBS or SIBO patients consume, likely to cause bloating, constipation, diarrhea, and pain due to the rapid fermentation process by the bowel bacteria, these foods would be considered High FODMAP food. On the other hand, the restriction of fermentable carbohydrates could relieve gastrointestinal symptoms [26-27,32-33]. The guideline to control these disease types is to do the nutrition sorting in the Low FODMAP [28-29,34-35].

The Low FODMAP diet has not been wellperceived in Thailand. Also, the disease is not wellknown among medical outsiders. The 'Low FODMAP' diet program for disease control would provide the most efficiency under healthcare practitioners' practical usage with patient diagnosis. However, only a small number of the medical staff in Thailand are specialized in this treatment as well as the academic content in various media on this topic. The limited content availability affected the credibility and practical usage in the medical industry. Accordingly, the encouragement of learning in Low FODMAP among medical staff, they would be considered as the primary tier audiences to be interested and significantly exposed to this content prior to normal audiences, even the gastrointestinal patients who are in need of Low FODMAP treatment regarding the 'Diffusion of Innovation Theory' by Everette Roger [30].

Communication Situation in Thailand: The Low FODMAP diet is significantly rising in Thailand, for example, the academic journal by Community 
Pharmacy Association (Thailand) [31] mentioned about 'Diet Therapy for Small Intestinal Bacterial Overgrowth (SIBO) symptom'; 'FODMAPs Diet and the Irritable Bowel Syndrome (IBS)', Assoc. Prof. Dr.Wantanee Kriengsinyos [32] and 'Irritable Bowel Syndrome and FODMAPs Diet', Monthira Maneerattanaporn [33] as mentioned in Thai Dietetic Association Conference 2020. There are also research by Akarawut Juntrapirat [34] in 'Effect of structured individual-based lifestyle low FODMAPS dietary advice compare with usual care low FODMAPS dietary advice in gastrointestinal symptoms and intestinal hydrogen gas production in patients with irritable bowel syndrome' and 'Effect of Carbohydrate ingestion on intestinal hydrogen gas production and symptom in non-constipation Irritable bowel syndrome patients compared with Carbohydrate from wheat or mungbean' by Sittikorn Linlawan [35].

The medical staff would unsurprisingly not have adopted Low FODMAP therapeutic nutrition for practical implementation in disease control either Irritable Bowel Syndrome (IBS) or Small Intestinal Bacterial Overgrowth (SIBO). On the other hand, the patients would pay attention to this alternative remedy since the Low FODMAP is closely related to their eating habits in everyday life. Nonetheless, the result would be limited only to traditional therapeutic methods when the patients inquire some questions to the doctors about Low FODMAP. The disapproval of Low FODMAP implementation would be replaced by conventional medication and difficult reactions due to hesitation to recommend this new dietary plan with insufficient information. As mentioned earlier, the clear communication of this content education to the healthcare and medical industry is prominently important to create the attitude change in dietary treatment for disease control in a wide range. The collective combination of essential modern prescription and Low FODMAP dietary plan for patient treatment could increase the possibility to relieve the disease severance.

According to Berlo's SMCR Model of Communication by David Berio, as published in 'The Process of Communication' book [2], clearly explained the four critical factors of the communication process.

1. Source: The credible content collection in which the medical staff consider of sufficient influence and full capacity for practical implementation in the medical industry

2. Message: The possible manner of mentioning Low FODMAP for Irritable Bowel Syndrome (IBS) and Small Intestinal Bacterial Overgrowth (SIBO) disease control

3. Channel: The top-rated searching channel for medical staff to elevate their potential in the industry

4. Receiver: The medical staff who closely associated with the Low FODMAP education for disease control, despite still be in a few numbers

On top of that, the number of credible sources for the FODMAP dietary program, including the implementation details are severely limited, particularly the FODMAP diet in Thailand - ingredients and various kinds of dishes have not been systematically organized for practical implementation. Thus, this valuable resource has still not been well-perceived in patient care in the medical industry.

\section{DISCUSSION AND CONCLUSION}

As in Thailand nowadays, there are varied nutrition recommendations for IBS and SIBO treatment from different information sources that make the perceptual deviation from the Low FODMAP causing 
the hesitation in the healthcare practitioners. Low FODMAP diet has not been widely communicated among the healthcare professional. Accordingly, the doctors would hesitate in practical use due to it doesn't mention in clinical practice guideline. The Low FODMAP cluster diet is discussed to be strongly recommended to medical staff, applying as a nutritional recommendation procedure for gastrointestinal disease control including Irritable Bowel Syndrome (IBS) and Small Intestinal Bacterial Overgrowth (SIBO) that come with unsatisfied symptoms affecting patients' life quality. The medical professionals would be able to extensively educate the adopted knowledge to society in a wider range via the up-to-date media platforms. Sooner or later, there is a possibility of developing the Low FODMAP diet with local Thai ingredients. Lastly, this method would draw credibility among the normal audiences who could implement this dietary program to relieve their gastrointestinal symptoms for better healthcare standards and life quality.

Abbreviations: $\quad$ FODMAP: Fermentable Oligosaccharide Disaccharide Monosaccharide and Polyols, IBS: Irritable Bowel Syndrome, SIBO: Small Intestinal Bacterial Overgrowth.

Competing Interests: The authors have no financial interests or conflicts of interest.

Authors' contribution: All authors contributed to this study.

Acknowledgment and Funding: The authors declare no acknowledgments or funding.

\section{REFERENCES}

1. UKEssays. Importance of Communication in Daily Life. [https://www.ukessays.com/essays/englishlanguage/communication-is-integral-to-human-life- english-language-essay.php?vref=1.] Retrieved April 6, 2021.

2. Berlo D.K: The Process of Communication. New York: Holt, Rinehart and Winston,Inc; 1960.

3. Ellis R, McClintock A. You Take My Meaning: Theory into Practice in Human Communication. London: Edward Arnold 1990, 71.

4. Schramm W., The Beginnings of Communication Study in America .Thousand Oaks, CA: Sage, 1997.

5. Seekhle Learning [https://www.seekhle.com/2018/07/barriers-to-effectivecommunication.html] Retrieved April 7, 2021.

6. Relivingmbadays [https://relivingmbadays.wordpress.com/2012/07/25/bar riers-to-communication/] Retrieved April 7, 2021.

7. Oberg EB, Frank E.: Physicians' health practices strongly influence patient health practices. J R Coll Physicians Edinb. 2009, 39(4): 290-1.

8. Surinprateep $\mathrm{P}$, Ratinthorn A, Limruangrong $\mathrm{P}$ : Factors influencing pregnant women's seeking of health information. Journal of Thailand Nursing and Midwifery Council 2019, 34(4): 95-107.

9. Whitehead K. Changing dietary behaviour: the role and development of practitioner communication. The Nutrition Society Irish Section Meeting : 18-20 June 2014; Proceedings of the Nutrition Society; 2015, 74:177-184.

10. Ratzan SC, Payne JG, Bishop C: The status and scope of health communication. J Health Commun 1996, 1(1):2541.

11. Schiavo R: Health Communication from Theory to Practice. John Wiley and Sons, Inc.; 2007.

12. Department of Provincial Administration, Ministry of Interior. Statistics Thailand's aging population 2020 [http://www.dop.go.th/download/knowledge/th1610815 306-335_0.pdf.] Retrieved March 10, 2021.

13. Cote J.: What is New Media? [https://www.snhu.edu/about-

us/newsroom/2020/02/what-is-new-media] Retrieved April 7, 2021.

$\begin{array}{llll}\text { 14. Beal } & \text { V.: } & \text { New }\end{array}$ [https://www.webopedia.com/definitions/new-media/] Retrieved April 7, 2021.

15. Kelman HC: Compliance, identification, and internalization: Three processes of attitude change. Journal of Conflict Resolution. 1958, 2(1) :51-60.

16. Cuoco L, Salvagnini M: Small intestine bacterial overgrowth in irritable bowel syndrome: a retrospective study with rifaximin. Minerva Gastroenterol Dietol. 2006, 52(1):8995. 
17. Ghoshal UC, Shukla R, Ghoshal U. Small intestinal bacterial overgrowth and irritable bowel syndrome: A bridge between functional organic dichotomy. Gut Liver. 2017, 11(2):196-208.

18. Ghoshal UC, Srivastava D: Irritable bowel syndrome and small intestinal bacterial overgrowth: meaningful association or unnecessary hype. World J Gastroenterol. 2014, 20(10): 2482-2491.

19. Bures J, Cyrany J, Kohoutova D, et al: Small intestinal bacterial overgrowth syndrome. World J Gastroenterol. 2010, 16(24):2978-2990.

20. International Foundation for Gastrointestinal Disorders [https://www.aboutibs.org/facts-aboutibs/statistics.html] Retrieved March 10, 2021.

21. Simren M, Mansson A, Langkilde AM, Svedlund J, Abrahamsson H, Bengtsson U, Bjornsson ES. Food-related gastrointestinal symptoms in the irritable bowel syndrome. Digestion 2001, 63(2):108-15.

22. Longstreth GF, Thompson W, Chey WD, Houghton LA, Mearin F, Spiller RC. Functional Bowel Disorder p.487-556. In Rome III: The Functional Gastrointestinal Disorders. Drossman DA, eds. Degnon Associates, Mclean, Virginia USA 2006.

23. Hill P, Muri JG, Gibson PR: Controversies and recent developments of the low-FODMAP diet. 2016, 13:36-45.

24. Harvard Health Publishing [https://www.health.harvard.edu/diet-and-weight-loss/anew-diet-to-manage-irritable-bowel-syndrome] Retrieved April 7, 2021.

25. Gibson PR, Shepherd SJ. Personal view: food for thought western lifestyle and susceptibility to Crohn's disease.The FODMAP hypothesis. Aliment Pharmacol Ther. 2005, 21(12):1399-1409.

26. Staudacher HM, Lomer MC, Anderson JL, Barrett JS, Muir JG, Irving PM, Whelan K: Fermentable carbohydrate restriction reduces luminal bifidobacteria and gastrointestinal symptoms in patients with irritable bowel syndrome. J Nutr 2012, 142(8):1510-1518.

27. Fisher K, Hutcheon D, Ziegler J: Elimination of fermentable carbohydrates to reduce gastrointestinal symptoms in pediatric patients with irritable bowel syndrome: A narrative review. Nutr Clin Pract 2020, 35(2):231-245.

28. Nanayakkara WS, Skidmore PM, O'Brien L, Wilkinson TJ, Gearry RB: Efficacy of the low FODMAP diet for treating irritable bowel syndrome: the evidence to date. Clin Exp Gastroenterol 2016, 9:131-142.

29. Ong DK, Mitchell SB, Barrett JS, Shepherd SJ, Irving PM, Biesiekierski JR, Smith S, Gibson PR, Muir JG: Manipulation of dietary short chain carbohydrates alters the pattern of gas production and genesis of symptoms in irritable bowel syndrome. J Gastroenterol Hepatol 2010, 25(8):1366-73.

30. Roger EM: Diffusion of Innovations. 5 thed. New York : Free Press; 1962.

31. Chaiyasit K, Permpoon V, Wutthikongsombat W. Therapeutic Nutrition for Small Intestinal Bacterial Overgrowth (SIBO). Journal of Community Pharmacy Association (Thailand) 2017, 95:53-58.

32. Kriengsinyos W. FODMAPs Diet and Irritable Bowel Syndrome. In Proceeding of the The Thai Dietetic Conference: 23-25 November 2020; Journal of The Thai Dietetic Association 2020, 40(1-3):91-94.

33. Maneerattanaporn M. Irritable Bowel Syndrome and FODMAPs Diet. In Proceeding of the The Thai Dietetic Conference: 23-25 November 2020; Journal of The Thai Dietetic Association 2020, 40(1-3):95-106.

34. Juntrapirat A. Effect of Structured Individual-Based Lifestyle Low Fodmaps Dietary Advice (Silfd) Compare with Usual Care Low Fodmaps Dietary Advice in Gastrointestinal Symptoms and Intestinal Hydrogen Gas Production in Patients with Irritable Bowel Syndrome. thesis. Chulalongkorn University, Department of Medicine; 2016.

35. Linlawan S. Effect of Rice Carbohydrate Ingestion on Intestinal Hydrogen Gas Production and Symptom in NonConstipation Irritable Bowel Syndrome Patients compared with Carbohydrate from Wheat or Mungbean. thesis. Chulalongkorn University, Department of Medicine; 2013. 